\title{
The Influence of Different Climatic Conditions on the Yield of Soybeans Cultivated under Different Population Densities
}

\author{
Y. Koesmaryono, H. Sugimoto, D. Ito, T. Sato and T. Haseba \\ (College of Agriculture, Ehime University, Matsuyama 790, Japan)
}

\begin{abstract}
The climatic conditions during the growth period in 1994 and 1995 were different from those in normal years. The longer sunshine duration, higher radiation intensity and higher air temperature were considered the important factors responsible for the higher yield in the present experiment. The yield of soybeans in the present experiment was higher and reached of $397-661 \mathrm{~g} \mathrm{~m}^{-2}$ more than the average yield of $302 \mathrm{~g} \mathrm{~m}^{-2}$ for Ehime Prefectural Experimental Station. The results obtained in the present experiment indicate that soybean plants have capacity to produce higher grain yield under the climatic conditions like that in 1994 and 1995.

The climatic conditions during the ripening stage were a little different between two years. Longer sunshine duration, higher radiation intensity and higher air temperature during the ripening stage in 1994 might have contribution to higher LAl and higher NAR and hence higher CGR. The higher CGR during the ripening staged in 1994 was consider to produce higher seed weight and hence higher seed yield.

Key words: climatic conditions, crop growth rate (CGR), population density, ripening period, soybean
\end{abstract}

\section{Introduction}

Soybean (Glycine max Merr.) is an important crops in developing countries because it fulfills people's demand for food, and particularly protein. Under global climate change, the increasing temperature and levels of atmospheric greenhouse gases may have implications for soybean production in the future.

Since radiation interception and distribution in the canopy are important factors for crop production and the spatial distribution of plants in the field is an inevitable determinant of yield. More information is needed to verify the influence of changes in climatic conditions on yield of soybean cultivated under different population density.

\section{Materials and Methods}

The field experiments were conducted at Ehime University, Matsuyama $\left(33^{\circ}\right.$

$50^{\prime} \mathrm{N}, 132^{\circ} 48^{\prime} \mathrm{E}$ ), Japan in 1994 and 1995. A determinate cultivar of soybean, Fukuyutaka, was grown on an alluvial-clay loam soil at three population densities of 26.7, 10.7, and 5.3 plants $\mathrm{m}^{-2}$ for high, medium and low density, respectively. Sowing date was June 30 in both years and prior to planting, $30,100,100$ and $1000 \mathrm{~kg} \mathrm{ha}^{-1}$ of N, $\mathrm{P}_{2} \mathrm{O}_{5}$, $\mathrm{K}_{2} \mathrm{O}$, and lime, respectively, were applied.

Climate data were collected from Matsuyama Meteorological Bureau. Plant growth was calculated by growth analysis methods. The sampling intervals were two or three weeks starting at 20 days after sowing (DAS) and yields components and yield were observed at harvesting. Six plants per plot were taken at each sampling.

\section{Results and discussion}

\section{Climatic conditions during the experiments.}

During the experiments, from July through early November 1994 and 1995, air temperature was higher and sunshine duration was longer than normal years (Fig. 1.) Meanwhile, during the ripening stage weather conditions between two years were slightly different. There was more rainfall in 1995 than in 1994. So that, sunshine duration 
and average radiation intensity were higher in 1994 than in 1995. Air temperature was also higher in 1994.
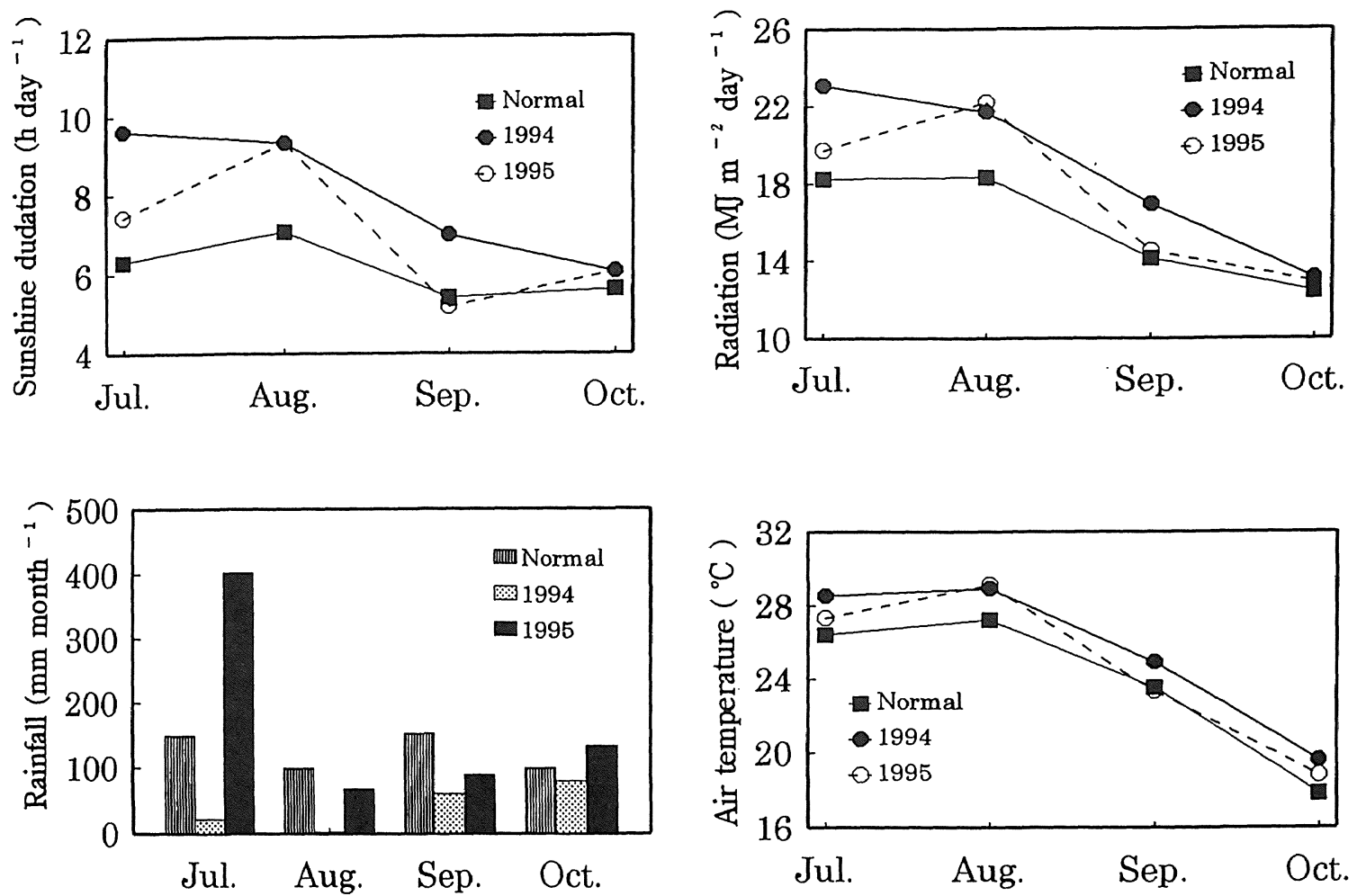

Fig. 1. Climatic conditions of Matsuyama in normal years, 1994 and 1995.

\section{Dry matter production and growth analysis}

Total dry matter and maximum LAI (leaf area index) were shown in Fig. 2. Under higher air temperature and higher radiation intensity, plant growth was vigorous in both years. The results indicate that the higher the density was, the higher the total dry matter and the maximum LAI. These values of each planting density in 1994 were a little bit higher than in 1995.
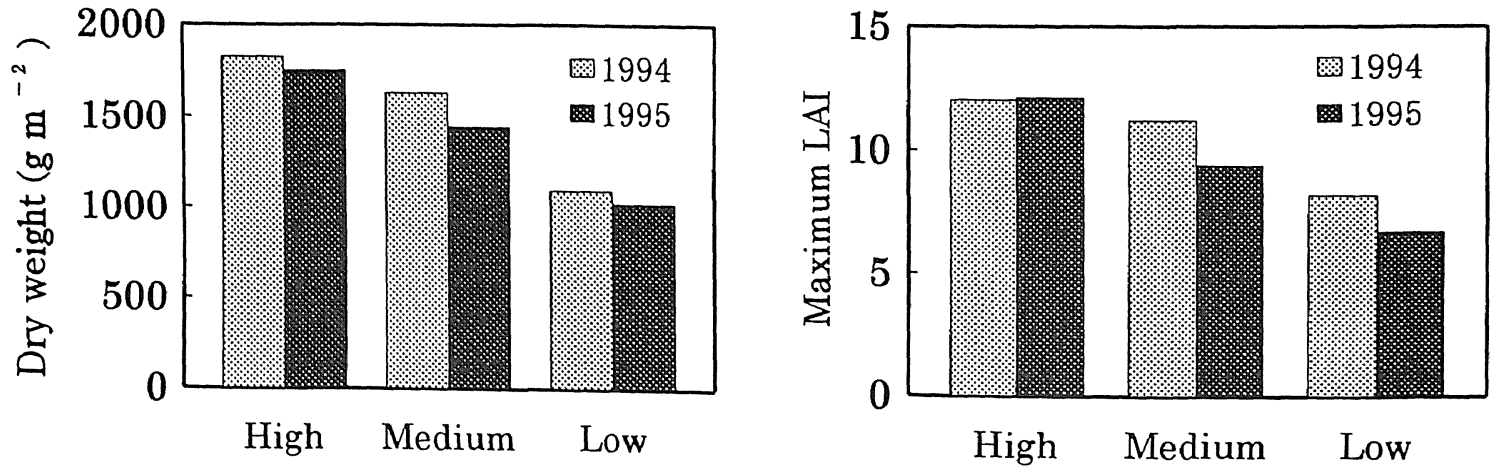

Fig.2. Total dry weight and maximum LAI. 
Using the data of dry weight an leaf area, CGR (crop growth rate), average LAI and NAR (net assimilation rate) during the vegetative and the ripening stage were calculated as shown in Fig. 3. The higher the planting density was, the higher the CGR in both years. During the vegetative stage, CGR were nearly the same between two years. However, due to higher average LAI and higher NAR during the ripening stage in 1994, CGR of all densities in 1994 were higher than in 1995.

In general, NAR decrease in the later period due to mutual shading and decreased capacity of photosynthesis. Although higher LAI, it was assumed that higher sunshine duration and higher radiation intensity during the ripening period caused higher NAR in 1994. And it would be also considered that depression in photosynthesis and reduction in LAI were inhibited during the ripening stage due to higher air temperature in 1994.
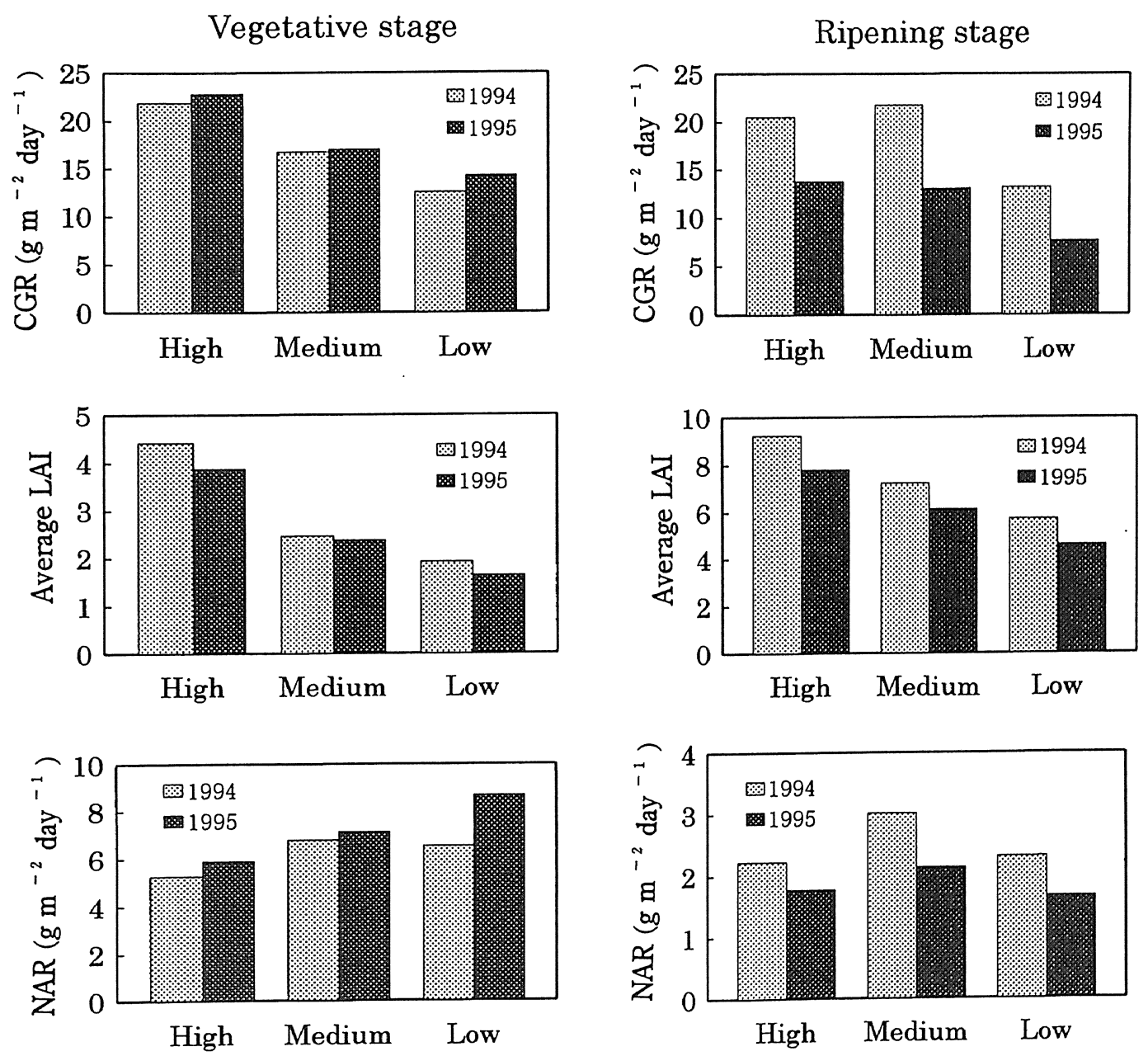

Fig. 3. CGR, average LAI and NAR in the vegetative and ripening stages.

\section{Yield components and grain yield.}

The results of yield component and grain yield were summarized in Table 1. The higher the density was the higher the yield in the present experiment. In this regards, Ikeda and Sato (1990) reported the same results that the higher density have 
produced the higher yield per unit area. Moreover, the yield of soybeans in the present experiment was higher than the average yield (302 $\mathrm{g} \mathrm{m}^{-2}$ ) of Ehime Prefectural Experimental Station (Takenouchi et al., 1993). These results can be attributed to an increase in the number of pods and the weight of seed. In the present study, vigorous growth developed more branches and nodes which produced higher number of pods. Longer sunshine duration, higher radiation intensity and higher air temperature during the present experiments were considered the important factors responsible for the higher yield (Koesmaryono et al., 1996).

As mentioned above, the grain yield were very high in both years than normal years, however, it was significantly higher in 1994 than in 1995 . Higher seed weight may responsible for higher yield in 1994. The higher seed weight was attributed to higher CGR during the ripening stage in 1994 than in 195.

Table 1. Yield and yield components.

\begin{tabular}{llcccc}
\hline Year & Density & $\begin{array}{c}\text { Number of } \\
\text { pods } \\
\mathrm{m}^{-2}\end{array}$ & $\begin{array}{c}\text { Number of } \\
\text { seeds } \\
\text { pod }\end{array}$ & $\begin{array}{c}\text { Weight of } \\
100 \text { seeds } \\
\mathrm{g}\end{array}$ & $\begin{array}{c}\text { Yield } \\
\mathrm{g} \mathrm{m}^{-2}\end{array}$ \\
\hline \multirow{3}{*}{1994} & High & 1298 & 1.48 & 35.67 & 660.85 \\
& Medium & 1083 & 1.51 & 39.07 & 628.02 \\
& Low & 785 & 1.42 & 39.89 & 444.25 \\
& High & 1266 & 1.41 & 35.71 & 637.94 \\
& Medium & 980 & 1.49 & 34.15 & 492.33 \\
& Low & 742 & 1.46 & 36.65 & 396.59 \\
& & & & \\
& & F values & & & \\
& Density & $62.29 * *$ & $1.61 \mathrm{~ns}$ & $1.64 \mathrm{~ns}$ & $72.41 * *$ \\
& Year & $2.84 \mathrm{~ns}$ & $0.56 \mathrm{~ns}$ & $9.67 * *$ & $19.27 * *$ \\
& Density $\times$ Year & $0.49 \mathrm{~ns}$ & $0.81 \mathrm{~ns}$ & $2.41 \mathrm{~ns}$ & $4.77 \mathrm{~ns}$ \\
\hline
\end{tabular}

** : Significant at 0.01 probability levels. ns : No significant.

\section{Conclusion}

The results obtained in the present experiments indicate that soybean plants have capacity to produce higher grain yield (about $600 \mathrm{~g} \mathrm{~m}^{-2}$ ) under such climatic conditions, higher radiation intensity, longer sunshine duration, higher air temperature and sufficient water supply.

Ikeda, $\mathrm{T}$, and Sato, $\mathrm{K}$ References soybean pelation between plant density and yield components in Koesmaryono, y.

Koesmaryono, Y., Haseba, T., Sugimoto, H., and Ito, D., 1996: Growth and yield of soybean cultivated under different population density with special reference to unusual summer weather in 1994. In Crop research in Asia: Achievements and perspective (ed. by R. Ishii and T. Horie). Proc. 2nd Asian Crop Sci. Conf.,
478-479.

Takenouchi, A., Shibata H., and Iwaki A., 1993: Effects of precipitation on the growth and seed yield of soybeans in an upland field converted from paddy. Bull. Ehime Agric. Exp. Sta., 32, 29 - 35. 